not overlooking work safety issues. All the experiments were be carefully documented using video and thermal imaging.

Results The tests revealed both the usefulness of agile extinguishing methods and their limitations. Also, several best practices for different extinguishing methods were defined. The new, agile extinguishing methods can clearly improve Fire \& Rescue response as the actual scene can be reached much faster than in the past.

Conclusions Fire \& Rescue services can improve their level of service by a choice of extinguishing method. This will also affect the extent of damage to both victims of an incident as well as buildings and other material.

\section{RESEARCHING CHILDREN'S EXPERIENCE OF TRAUMATIC EVENTS; EXPLORING CHILD BEHAVIOUR IN DWELLING FIRES}

Julie Mytton, Trudy Goodenough, Claire Novak, Jane Hughes, Julie Woodley. University of the West of England, Bristol, UK

\subsection{6/injuryprev-2016-042156.106}

Background Understanding child behaviour during injury-risk events supports development of injury prevention education and interventions, but asking children to recall events may cause distress. We found an absence of published evidence on childreported behaviour in accidental dwelling fires. Therefore we aimed to develop methods to; identify and recruit families who had an accidental fire at home; enable families to tell their stories with minimal distress, and test the feasibility of such methods for a future study.

Methods Consultation with frontline, educational and strategic staff in the Devon and Somerset Fire and Rescue Service (DSFRS), parents, young people, the mother of a burned child and working with a clinical psychologist and ethics committee Chair informed the development of methods for family identification, recruitment and participation. The DSFRS identified dwelling fires in the previous 12 months and sent study information inviting families to contact the research team.

Results Leaflets sent to 218 households resulted in 8 enquiries (3.7\% response) and 3 families recruited (1.4\% participation). Families were more likely to engage if contacted 3-6 months after the fire than if $>6$ months. Five parents and 6 children took part. Face-to-face interviews included a meeting with the parents alone to learn about the fire and negotiate arrangements for the children's interview, conducted later that day, led by a psychology researcher. Art materials enabled children's storytelling and strategies provided to stop the interview if children became distressed. Support for families and researchers after the interviews was required.

Conclusions Engaging families in qualitative studies of potentially distressing injury-risk events requires extensive preparation, flexibility and negotiation. Examples of materials and learning from this study will be presented and may be applicable to other injury research studies where hearing the voice of the child is paramount.

\section{DIFFERENCES IN DETERMINANTS AMONGST INDIVIDUALS REPORTING RESIDENTIAL FIRES IN SWEDEN- RESULTS FROM A CROSS-SECTIONAL STUDY}

Finn Nilson, Carl Bonander, Anders Jonsson. Division of Risk Management, Department of Environmental and Life Sciences, Karlstad University, Karlstad, Sweden

\subsection{6/injuryprev-2016-042156.107}

Background Whilst determinants for fire mortality and morbidity are well documented, the determinants of residential fires, regardless of outcome, are less known. This study aimed to investigate socio-demographic differences between households having experienced a fire and those who had not.

Method Using a cross-sectional study design, a questionnaire was sent to a stratified sample $(n=20,000)$ of the Swedish population regarding if the household had experienced a fire during the past 5 years. Pearson's $\chi^{2}$-test was used to test for bivariate associations between residential fires and socio-demographic covariates, and log-binomial regression models were applied to obtain covariate-adjusted risk ratios.

Results Significant factors associated with an increased risk of residential fires were a high education level, being born outside of the Nordic countries and having children 6-12 years living at home. A significant decreased risk was observed amongst elderly and those living in rented, multi-family houses.

Discussion There seems to be a lack of agreement between determinants for fires and for fire mortality. This would indicate that the risk of fire mortality per residential fire is greatly increased for certain groups and that the increased risk of fire mortality is not due to a more common occurrence of fires.

Published in Fire Technology, May 2015, Volume 51, Issue 3, pp 615-626

\section{MEASURING THE EFFECTIVENESS OF FIRE PREVENTION}

Laine Tuomas. University of Tampere, Finland

10.1136/injuryprev-2016-042156.108

Background Evaluation of the effectiveness of public undertakings has become more and more important during the last decades. This is a major concern also in the field of fire safety. Yet, little progress has been made since the 1970's and there still is no consensus on the proper way to measure the effectiveness of fire prevention programs.

In Finland, fire prevention has for long been a notable part of the rescue service. Lately, fire department databases, data collecting processes and standards have improved, and much work has been done to collect relevant information concerning fire prevention impacts, risk variation of target groups and condition variables related to accidents. However, more tenable measures and better knowledge on the causal effects of the programs are still needed.

Methods The data consist over 350,000 observations of different fire prevention initiatives in six regions and over 800,000 buildings covered by regional fire departments between 2008 and 2014. In addition, data collected from the national accident 
database consist over 13,000 accidents with outcome variables like frequency of accidents, fire related damages and nuisances, and fire deaths.

Results Evaluation of fire prevention programs is examined from two viewpoints. First, the results concern the requirements on information management. The relevant information concerning the costs, effects and risks for accurate utilisation of the method in strategic and operative conduct of fire services is pinpointed. Second, the study exposes the limitations and challenges in measuring the effectiveness of fire prevention. The variation in the key explanatory variables is used to identify their effects on outcome variables in order to study the causal effects of fire prevention.

Conclusions The Analysis is still a work in progress. The conclusions are expected to be completed by the end of 2015 .

\section{ASSESSING THE NUMBER OF FIRE FATALITIES IN A DEFINED POPULATION}

${ }^{1}$ Anders Jonsson, ${ }^{2}$ Anders Bergqvist, ${ }^{1}$ Ragnar Andersson. ${ }^{1}$ Karlstad University, Sweden; ${ }^{2}$ Swedish Fire Protection Association, Sweden

10.1136/injuryprev-2016-042156.109

Background Fire-related fatalities and injuries have become a growing governmental concern in Sweden, and a national vision zero strategy has been adopted stating that nobody should get killed or seriously injured from fires. There is considerable uncertainty, however, regarding the numbers of both deaths and injuries due to fires. Different national sources present different numbers, even on deaths, which obstructs reliable surveillance of the problem over time. We assume the situation is similar in other countries. This study seeks to assess the true number of firerelated deaths in Sweden by combining sources, and to verify the coverage of each individual source. By doing so, we also wish to demonstrate the possibilities of improved surveillance practices.

Methods Data from three national sources were collected and matched; a special database on fatal fires held by The Swedish Contingencies Agency (nationally responsible for fire prevention), a database on forensic medical examinations held by the National Board of Forensic Medicine and the cause of death register held by the Swedish National Board of Health and Welfare.

Results The results disclose considerable underreporting in the single sources. The national database on fatal fires, serving as the principal source for policymaking on fire-prevention matters, underestimates the true situation by $20 \%$. Its coverage of residential fires appears to be better than other fires.

Conclusions Systematic safety work and informed policy-making presuppose access to correct and reliable numbers. By combining several different sources, as suggested in this study, the national database on fatal fires is now considerably improved and includes regular matching with complementary sources.

\section{PROTECTING CHILDREN FROM FIRE AND BURN INJURIES IN PUNE THROUGH TRAINING AND AWARENESS}

Cinthia Pinto. Safe Kids Foundation, India

10.1136/injuryprev-2016-042156.110

Background Fire and burn injuries pose a serious risk to all especially to young children. Burn injuries often take a long time to heal and are either not entirely reversible or extremely expensive to treat in India. As per World Health Organisation report, around 265,000 deaths are caused by burns every year especially in low economic countries and globally nearly 96,000 children under the age of 20 were estimated to be fattlly injured as a result of fire realted burns in 2004. Fire incidents are on the rise even in Pune. In 2014, it is estimated that around 76,000 children sustained burn injuries in Pune alone and out of these around 2980 suffered third degree burns. The highest number of burn injuries occurred in the age group of $7-10$ years. $64 \%$ of the burn injuries happened at home.

Methods Safe Kids foundation India (SKFI) undertook extensive research conducted by IMRB international to understand preventable child injuries in Pune. Based on the findings SKFI has developed bilingual educational materials and safety messages. With the help of these, we will conduct training and create awareness among children and adults.

Objective Reduce fire, burn and scald injuries among children below 14 years of age in Pune by creating awareness that aim to change the behaviours.

Results The campaign will reach out to 325,000 students below 14 years of age and 175,000 parents in 3 years through community events and class room sessions. Educational and awareness efforts in schools \& communities and rising mindfulness among caregivers will result in protecting children from fire and burn injuries.

Conclusions The statistics are alarming, and there are global concerns as well. Change of behaviour on the part of parents and children will pave the way for a safe environment in Pune. SKFI is exploring opportunities to extend education and outreach efforts in other states in India such as Bangalore and Gurgaon.

\section{Burden of Injuries}

\section{Parallel Mon 1.7}

\section{FROM LOSS OF LIFE TO LOSS OF YEARS: SWEDISH INJURY FATALITIES FROM ANOTHER PERSPECTIVE}

'Linda Ryen, ${ }^{2}$ Mikael Svensson. ${ }^{1}$ Swedish Civil Contingencies Agency, Sweden; ${ }^{2}$ Sahlgrenska Academy, University of Gothenburg, Sweden

\subsection{6/injuryprev-2016-042156.111}

Background Traditionally, the burden of injury deaths is presented as the number of fatalities due to different injury types. In Sweden, the greatest number of accidental deaths is caused by falls followed by poisonings and road traffic accidents. There is however large differences among injury types when it comes to the age profile among those affected. By taking this into account, the distribution of the burden of injury among injury types will change dramatically.

Methods Using life expectancy tables and statistics on age, sex and type of injury for the victims, the plain number of fatalities due to injuries is converted to the sum of potential years of life lost due to injuries in Sweden for the time period 1972-2014.

Results Changing the perspective from counting the number of fatalities to summing the number of potential years of life lost according to life expectancy tables, dramatically changes which injury types cause the greatest burden on society.

The total number of life years lost due to injuries in 2014 amounts to about 108,000 of which almost half were lost due to accidents (unintentional injuries). Suicide account for about 25 